\title{
Analysis of local cutting edge geometry on temperature distribution and surface integrity when dry drilling of aeronautical alloys
}

\author{
G. Le Coz, M. Jrad, P. Laheurte, D. Dudzinski \\ Laboratoire d'Etude des Microstructures et de Mécanique des Matériaux (LEM3), UMR CNRS \\ 7239, Université de Lorraine, 4 rue Augustin Fresnel, 57070 Metz, France \\ gael.lecoz@univ-lorraine.fr
}

\begin{abstract}
A suitable choice of tool geometry and tool material and the optimization of cutting conditions is the way towards dry machining, especially for difficult to machine materials. The current paper proposes an experimental work about dry drilling of AA 7075 aluminium and more particularly Ti-6Al-4V titanium alloys. Effects of complex drill geometry on thrust force and cutting temperature variations are explored. This study includes drill normal rake angle definition using a mathematical formulation based on tool CAD definition. Temperature distribution along the drill cutting edge is estimated with a specific device. Cutting forces are measured using a dynamometer table. Hole surface integrity is studied by observation of microstructures, on surface and sub-surface. Micro-hardness tests complete the measurements. Results show that temperature is much higher when drilling titanium Ti-6Al-4V than when drilling aluminium AA7075, with variations from $450^{\circ} \mathrm{C}$ to $540^{\circ} \mathrm{C}$ along the main cutting edge. Temperature variation along the cutting edge depends on cutting speed, work material and local geometry. Microstructural observations reveal that surface and sub surface are affected with grains elongation in cutting direction. Temperature and microstructural deformation increase with drilling depth.
\end{abstract}

Keywords. Drilling, Temperature, Surface integrity, AA7075 Aluminium alloy, Ti-6AI-4V titanium alloy.

\section{INTRODUCTION.}

In order to reduce weight and increase performance of structures, aluminium and titanium alloys are widely used in the aeronautical industry. The main reasons for their use are their low density and their very good combination of mechanical and metallurgical properties.

Today, industries must minimize their waste streams and manage better the impact of their activities on the environment. The metalworking sector, including aerospace industries, is particularly concerned. As a consequence, attention must be paid on the role of cutting fluids during machining [1]. The solution is to reduce the use lubricants. Eliminating or minimizing cutting fluids has another advantage, it reduces the manufacturing costs.

Dry or semi-dry machining of aluminium alloys is now an industrial reality, but its application for titanium alloys and in particular for machining Ti-6Al-4V is not evident. This alloy is ranked among difficult to machine materials [2]. The chemical reactivity of titanium with the tool generates bonding by adhesive phenomenon, leading to a significant chipping and premature tool wear. Moreover, when cutting, titanium induces a localized shear band and maintains its mechanical characteristics even at high temperatures. In combination with its thermal low conductivity, its high mechanical characteristics lead, during machining, to high temperatures at the tool-workpiece interfaces. High thermal and mechanical loads during machining may induce residual stresses and metallurgical alterations such as microstructural distortion and phase transformation. These effects are localized in the machined sub-surface for a depth of between a few micrometers [3] to more than 100 microns [4].

A suitable choice of tool geometry and tool materials (substrate and coatings) and the optimization of cutting conditions is the way towards dry machining.
This paper presents the effect on temperature distribution along the cutting edge and on surface integrity of dry drilling AA 7075 aluminium alloy and of dry drilling Ti-6Al$4 \mathrm{~V}$ titanium alloy. For these operations, minimizing the cutting temperature is surely the key to optimize cutting parameters.

Several techniques have been developed over time for the measurement of temperature in various manufacturing processes. They include principally thermocouples (the embedded thermocouple and the dynamic thermocouple or the chip-tool thermocouple), infra-red photography; optical infrared radiation pyrometers, Davies et al. [5]; most concerns turning operations. Measuring cutting temperature during drilling is more complex due to the process itself. The tool rotates and the cutting action is confined. Some experimental techniques have been proposed to overcome these difficulties.

De Vries et al. [6] were probably the first to determine drill temperature with iron-constantan embedded thermocouples and to study the effect of drill design variables on drill temperature responses. Kalidas et al. [7] employed thermocouples at different locations of the workpiece and along the hole to measure the maximum temperature rise. They used this temperature rise as a parameter to compare three different coatings in dry and wet drilling conditions. Ozcelik and Bagci [8], studied the influence of spindle speed and feed rate on the drill temperature responses. Experimental study was conducted by using two different workpiece materials, AISI 1040 steel and Al 7075-T651. They developed a new experimental setup; a thermocouple was inserted through the oil hole of internal coolant carbide drill and fixed closed to the drill bit. The drill was put into a specially fixture and fixed on a dynamometer fixed on the machine table; the experiment samples were cylindrical mounted in the spindle chuck instead of the drill. A similar experimental 
setup was used by $\mathrm{Li}$ and Shih [9] to study drilling of Ti$6 \mathrm{Al}-4 \mathrm{~V}$ in wet and dry conditions. Zeilmann and Weingaertner [10] studied the effects of cutting conditions and of hard coatings on the workpiece temperature during drilling Ti-6Al-4V with minimal quantity lubricant. The temperature was measured at different locations as closed as possible to the hole wall $(0.2 \mathrm{~mm})$. Recently, Sato et al. [11] measured the temperature of the newly generated surface of the drill tip by using an optical fibre is inserted into the oil hole of the internal coolant carbide drill. The drilling tests were conducted on a conventional lathe and a 304 stainless steel, and a Ti-6Al-4V titanium alloy were used as workpieces. When drilling Ti-6Al-4V, the temperature increases gradually and then rapidly near the bottom of the workpiece. At a depth of $10 \mathrm{~mm}$, a temperature of $480^{\circ} \mathrm{C}$ was measured for a cutting speed of $33 \mathrm{~m} / \mathrm{min}$ and a feed rate of $0.1 \mathrm{~mm} / \mathrm{rev}$.

Another concern is the temperature distribution along the cutting edge. Li et al. [9] proposed a finite element thermal model using the inverse heat transfer model to find the heat partition on the tool-chip contact area and determine the temperature distribution at the drill tip. Increasing the cutting speed from 24.4 to $73.2 \mathrm{~m} / \mathrm{min}$, when drilling Ti-6Al$4 \mathrm{~V}$, they found that the location of peak temperature moved outside toward the drill margin. By measuring temperature with optical fibres inserted in the workpiece at different positions from the centre of the drill, similar observations were made by Ueda et al. [12] when drilling the AISI 1045 steel and Beno and Hulling when drilling various work materials including Ti-6Al-4V [13].

To measure temperature all along the cutting edge, Bono and $\mathrm{Ni}$ [14] realized a dynamic thermocouple between the drill tip and a constantan foil placed in the workpiece. When drilling an aluminium alloy, the authors found that the maximum temperature occurs on the chisel edge, and that the temperature decreases with radius and reaches its minimum value near the ends of the primary cutting edges.

The aims of this experimental work were to focus on the links between drill geometry, cutting forces, cutting edge temperatures and microstructural changes in the machined subsurface. To perform this study, AA 7075 aluminium alloy and Ti-6Al-4V titanium alloy, commonly used by the aeronautical industry, were used as workpiece materials. The temperature distribution along the drill cutting edge was obtained using an experimental setup based on the one developed by Bono and $\mathrm{Ni}$ [14]. The integrity of the machined surfaces was analysed by the observation of the microstructure and the measurement of the micro-hardness profile in the subsurface.

\section{EXPERIMENTAL METHOD.}

\subsection{Experimental procedure.}

Dry drilling tests were performed on a Roeders RP600 high-speed machining centre. Two aeronautical materials were selected for the workpieces: the AA7075 aluminium and the Ti-6Al-4V titanium alloy. The same cutting conditions were selected for the two materials, defined by a cutting speed of $30 \mathrm{~m} / \mathrm{min}$, a feed rate of $0.1 \mathrm{~mm} / \mathrm{rev}$ and a final depth of drilling of $16 \mathrm{~mm}$.

Cutting forces were measured using a Kistler 9265B piezoelectric dynamometer associated to a Kistler 5017B charge amplifier. Temperature along the cutting edge was obtained by using a special device described in the following. The integrity of the drilled surface and subsurface were analysed through the micro-hardness profiles determination and the microstructure observation.

Table 1 Cutting conditions.

\begin{tabular}{lcc}
\hline Material & AA 7075 & Ti-6Al-4V \\
\hline Cutting speed $(\mathrm{m} / \mathrm{min})$ & & 30 \\
Feed rate $(\mathrm{mm} / \mathrm{rev})$ & & 0.1 \\
Drilling depth $(\mathrm{mm})$ & \multicolumn{2}{c}{16} \\
$\begin{array}{lc}\text { Measurement depth (L) } \\
(\mathrm{mm})\end{array}$ & 12 & $4 ; 12$ \\
\hline
\end{tabular}

An uncoated K40 (10\% cobalt) carbide drill with fine grains and referenced Diager 21731 was used. The diameter of the twist drill was of $10 \mathrm{~mm}$ with a point angle of $145^{\circ}$ and a helix angle of $15^{\circ}$. The particular drilling geometry such as the cutting angle and the inclination angle vary along the cutting edge. Using a mathematical formulation based on the CAD drill definition [15], statics normal rake angle are calculated and presented figure 1 (b). The cutting edge is divided in two major zones. The first quarter $(0<r / R<0.23)$ correspond to the thinning and the chisel edge and the second area $(0.23<r / R<1)$ correspond to the drill flute grinding. The crossing from the two areas is characterized by a discontinuity. Four minor areas are defined, see figure $1(\mathrm{~b})$. The thinning allows to limit a high negative angle at the near drill centre $(0.13<r / R<0.23)$. However, the first tenth of tool diameter are considered with a high negative angle $(0<r / R<0.13)$. Also, negative angle appears for $0.23<r / R<0.4$ followed by a positive angle for $0.4<r / R<1$.
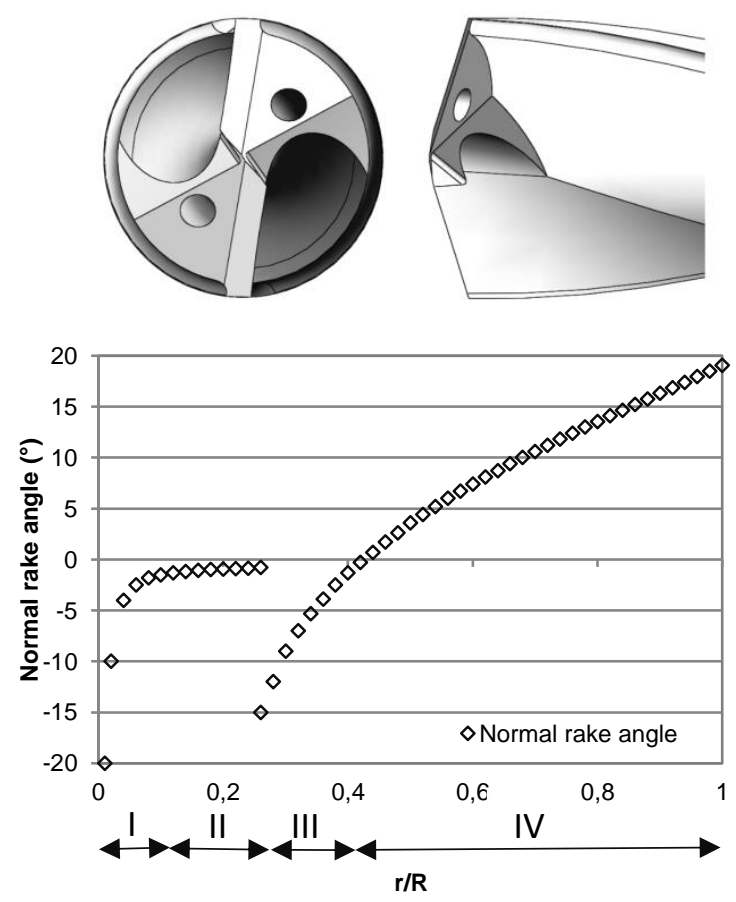

Fig. 1 (a) CAD definition and (b) evolution of normal rake angle of tool 


\subsection{Temperature measurement device}

An experimental device was developed based on a technique of dynamic thermocouple and whose effectiveness has been demonstrated previously [14]. The device is based on the Seebeck effect, corresponding to the occurrence of an electromotive force in a closed circuit consisting of two different conductors, when the junctions are at different temperatures. The thermocouple proposed is composed of the drilling tungsten carbide tool, and a 20 $\mu \mathrm{m}$ thin sheet of constantan. The sheet is positioned in the workpiece at a depth $L$, insulated from the workpiece by sheets of mica, see figure 2. When the drill contacts the foil, a junction is formed between the carbide hot drill and the constantan foil; it corresponds to the hot junction of the thermocouple. The cold junction is realised at room temperature through the copper wires. The temperature distribution along the chisel edge and the drill lips is obtained when the drill passes through the foil, and when the hot junction moves from the drill axis to the extremity of the drill diameter.

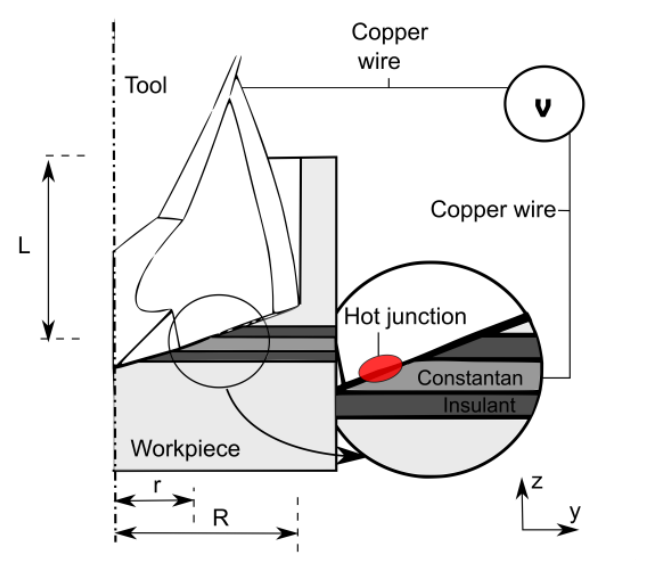

Fig. 2 Fundamental principle of the cutting edge temperature measurement.

A typical signal obtained with the dynamic thermocouple is shown figure 3 . At the beginning of the drilling process, the voltmeter measures only the noise associated with the antenna effect of its components. When the drill contacts the foil, a thermoelectric junction is formed between the hot drill and the foil. A voltage difference is measured, it corresponds to the difference temperature at the hot junction, namely at the interface between the tool and the sheet. As long as the drill passes through the constantan sheet, the hot junction is maintained; then it is no longer ensured and electrical noise is again measured.

The thermocouple composed by the tool material and the constantan sheet was calibrated by using a ceramic heater in which the temperature is measured by using an inserted normalized thermocouple. The constantan foil was heated in contact with the ceramic heater to a peak; then, the carbide tool was placed in contact with the sheet, and the heating was stopped. The decrease in temperature and the electromotive force generated by the constantancarbide thermocouple were measured. Calibration was carried out for temperatures from 100 to $400{ }^{\circ} \mathrm{C}$, figure 4 . A linear relation was obtained between electromotive force and temperature. This linearity is supposed true for higher measured temperature range obtained during the experimental study.

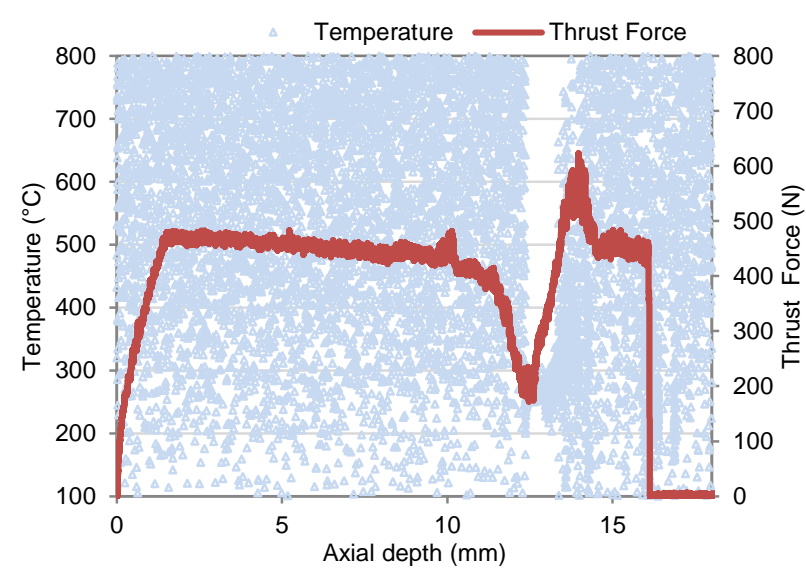

Fig. 3 Typical signal of thrust force and temperature when drilling aluminium

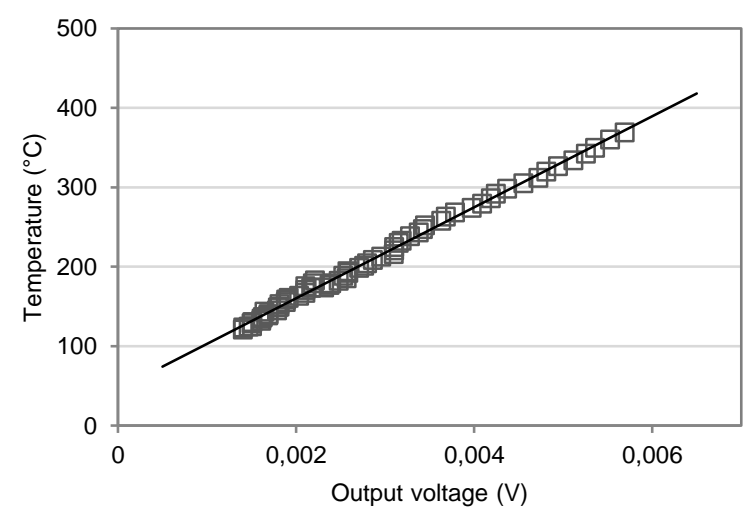

Fig. 4 Calibration curve of thermoelectric couple.

It should be noted that the presence of the sensor minimizes the real temperature of the cutting edge. Indeed, before cutting the constantan foil, each cutting edge element cuts the insulation mica sheet, and not the work material, and, on a half-thickness of the mica-constantan sandwich. Cutting and feed forces are thus reduced for a short time, observable on figure 3 . It is assumed that the associated temperature reduction is low due to the thermal inertia.

During drilling, the temperature measurements were performed at two different depths (4 and $12 \mathrm{~mm}$ ) depending on the position of the sheet of constantan in the workpiece before reaching the end of drilling operation at $16 \mathrm{~mm}$ depth.

\subsection{Surface integrity}

Only the titanium alloy workpiece was concerned by the surface integrity observations. After drilling, different sections of the workpiece were examined to study the microstructural changes in the drilled subsurface. These observations were performed for different depths and different planes (A,B,C,D and E), see figure 5 . Metallographic samples were sectioned to the areas of interest. To minimize damage, which may alter the microstructure and produce false metallographic characterization, propeting conditions were required. The specimens were then encapsulated into a mounting resin and polished with care. A chemical etching was finally performed to reveal microstructural features such as grain 
size and phase features. The specimens were observed with a Zeiss optical microscope.

To complete microscopic observations, microhardness testing was performed on the examined cross-sections. Microhardness profiles, in the perpendicular direction to the hole axis and from the drilled surface, were obtained using a Knoop indenter Zwick ZHV1 with a load of $100 \mathrm{~g}$.

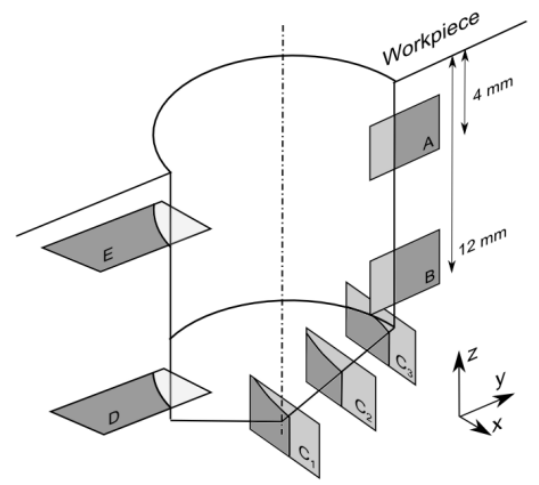

Fig. 5 Location of surface and sub-surface observations.

\section{RESULTS AND DISCUSSION.}

3.1 Material and drill geometry influence on temperature level and distribution.

Part of the temperature signal of figure 3 , corresponding to the contact between the carbide tool and the constantan sheet, was selected. The signal was smoothed by using a discrete low pass filter. The obtained temperature signal, for a drilling depth of $12 \mathrm{~mm}$, and for aluminium and titanium alloys workpieces are presented figure 6 .

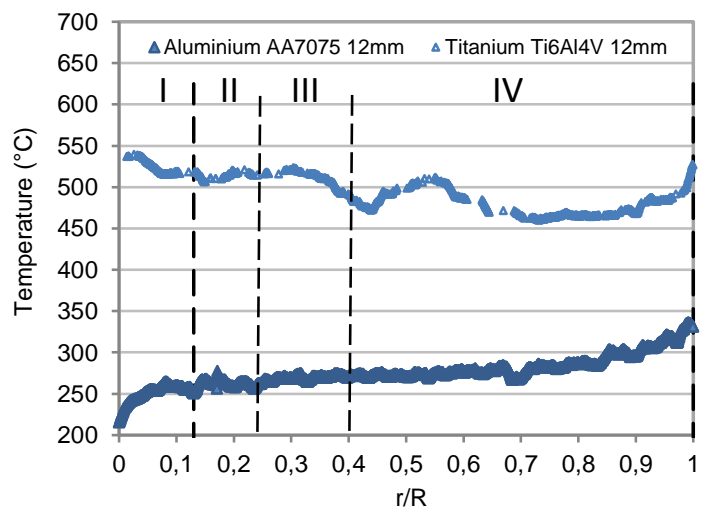

Fig. 6 Cutting edge temperature at a $12 \mathrm{~mm}$ drilling depth.

The temperatures when drilling aluminium are lower than when drilling titanium. For a depth of drilling of $12 \mathrm{~mm}$, the measured temperature varies along the cutting edge from $220^{\circ} \mathrm{C}$ to $340^{\circ} \mathrm{C}$ for aluminium alloy and from $460{ }^{\circ} \mathrm{C}$ to $550^{\circ} \mathrm{C}$ for titanium alloy. Indeed, the low thermal conductivity and the high mechanical properties of Ti-6Al$4 \mathrm{~V}$ with respect to those of aluminum AA7075 (respectively $7 \mathrm{~W} / \mathrm{mK}$ and $155 \mathrm{~W} / \mathrm{mK}$ at room temperature, for the conductivity) result in higher level of temperatures at the vicinity of the tool-workpiece interface. The obtained temperature levels are comparable with those measured by Ozcelik et al. [7], Li et al. [9] and Sato et al. [11], with other experimental devices. However, according to the results of Chen [16], these temperatures are low; using a tool-workmaterial thermocouple, the authors showed that continuous cutting of titanium alloy may generate temperatures up to $1100^{\circ} \mathrm{C}$. Note that the hot junction of the proposed thermocouple measures the temperature in the vicinity of the cutting edge. During a cutting process, the maximum temperature is generally obtained at the toolchip interface, just after the cutting edge.

The kinematics of the drilling process involves varying continuously cutting speed along the cutting edges of the drill, from zero at the drill tip to a maximum value at the periphery.

In the first area (I), cutting speed varies only from 0 to 3.9 $\mathrm{m} / \mathrm{min}$. Also, even the drill thinning, a high negative angle is present for $0<r / R<0.13$. Due to the combination of low speed and unadapted negative geometry at the centre part of the drill, the work material is not actually cut, but extruded, resulting in a significant penetration effort, figure 7. This area is generally called indentation area. When drilling titanium alloy, the penetration force is particularly important $(260 \mathrm{~N})$ with respect to that which exists when drilling aluminium alloy $(130 \mathrm{~N})$. As a consequence, the deformation energy converted into heat at the tool tip is more important for the titanium alloy than for the aluminium alloy; this explains the large difference between the temperatures measured in this zone during the drilling of these two materials, see figure 6 .

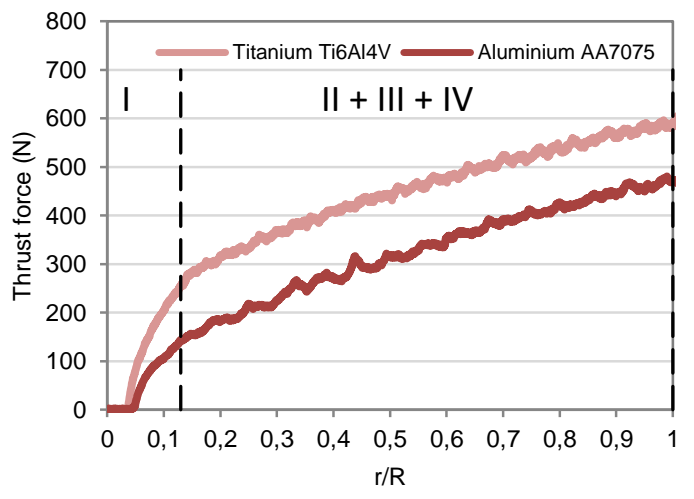

Fig. 7 Thrust force at the material entrance.

The temperature distribution is another difference, figure 6 . When drilling aluminium, the temperature increases rapidly from the tool tip to the end of the first area (I), from $210^{\circ} \mathrm{C}$ to $260{ }^{\circ} \mathrm{C}$. On the other hand, in the same area, when drilling titanium, temperature decreases slightly. Such phenomenon may be explained by the low thermal conductivity and the high mechanical properties of Ti-6Al$4 \mathrm{~V}$ associated to the sensitivity of titanium to the influence of cutting angle ; it is well known that a negative angle is not adapted when cutting titanium and generates particularly high temperature in the tertiary shear area.

In the second zone (II), for $0.13<r / R<0.23$, cutting speed increases and normal rake angle is stable, near to $0^{\circ}$. In the same area, temperatures are stable for titanium and aluminium, respectively 520 and $260^{\circ} \mathrm{C}$.

In the third and fourth zone (III) and (IV), for $0.23<r / R<1$, cutting speed and normal rake angle vary respectively from $6.9 \mathrm{~m} / \mathrm{min}$ to $30 \mathrm{~m} / \mathrm{min}$ and $-15^{\circ}$ to $20^{\circ}$. The thrust curves in the same area are parallel, figure 7 , revealing that contribution of each cutting edge element is similar, 
and for the two materials. Nevertheless, temperature variations appear, figure 6 . When drilling aluminium alloy, a slight temperature increasing is observed, from $260{ }^{\circ} \mathrm{C}$ at $r / R=0.23$ to $280{ }^{\circ} \mathrm{C}$ at $r / R=0.8$, followed by a larger increase, up to $340{ }^{\circ} \mathrm{C}$ near the margin. When drilling titanium, the temperature varies slightly from 510 to $460{ }^{\circ} \mathrm{C}$ along the cutting edge. It is interesting to note an increase of temperature for titanium near $r / R=0.5$. It could be influenced by the internal lubricant hole of the drill, modifying thermal conductivity into the tool. A temperature increase of $530{ }^{\circ} \mathrm{C}$ appears near the margin. At tool diameter, temperature increase is also influenced by margins that slide against the drilled hole, leading to a new heat source.

Variations are the results of a competition between cutting speed elevation (the higher the cutting speed, the higher the temperature is) and the cutting angle variation (the higher the positive cutting angle, the lower the temperature is). Temperature when cutting titanium seems to be more sensitive to cutting angle than cutting speed, contrary to aluminium cutting. The low thermal conductivity of Ti-6Al$4 \mathrm{~V}$ furthers the local thermal phenomenon of each cutting edge element and it characteristics. Then, variation of tool geometry begin an important parameter to be considered when study temperature distribution of drilling tool.

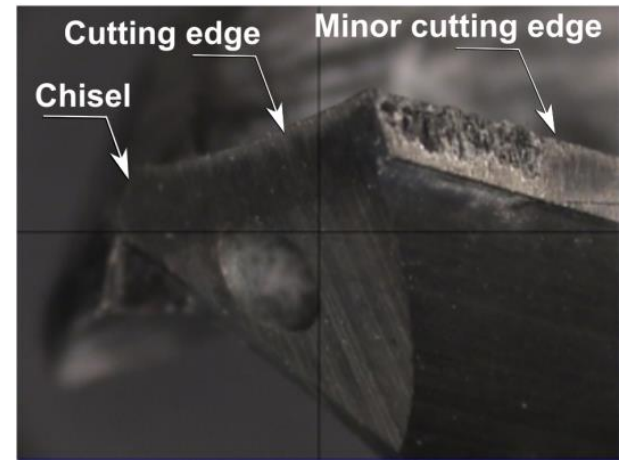

Fig. 8 Tool after drilling titanium Ti-6Al-4V.

\subsection{Influence of drilling depth on temperature level and distribution.}

The temperature distribution along the cutting edge, for two drilling depths, 4 and $12 \mathrm{~mm}$, are presented figure 9 . The two temperature distributions are very similar: a maximum is measured at the tool tip, and then the temperature decreases and stabilizes along the major part of cutting edge, around the value $400{ }^{\circ} \mathrm{C}$ for the drilling depth of $4 \mathrm{~mm}$, and $500{ }^{\circ} \mathrm{C}$ for the depth of $12 \mathrm{~mm}$; and increases at the tool diameter. In orthogonal cutting, a thermal steady state phenomena is rapidly attained (after a few tenths of seconds); however, in drilling process of Ti$6 \mathrm{Al}-4 \mathrm{~V}$ with MQL lubrication, a previous study [17] has shown a continuous increased of the tool temperature, due to the confinement of the drilling operation and the gradual displacement of the cutting zone inside the workpiece. All the heat generated by the cutting process and the friction is not evacuated by conduction in the workpiece and the length required to evacuate this heat varies throughout the drilling process. The accumulated heat in the tool causes a general temperature increase of the cutting edges.

Continuous chips are obtained when drilling titanium, their morphology may be decomposed into three regions, figure $9:$ an initial spiral cone formed at the start of drilling followed by a steady state spiral cone and finally a folded long ribbon chip, as observed by $\mathrm{Li}$ et al. [9]. The third region is the results of an increased difficulty for chip evacuation which corresponds to resistance forces.

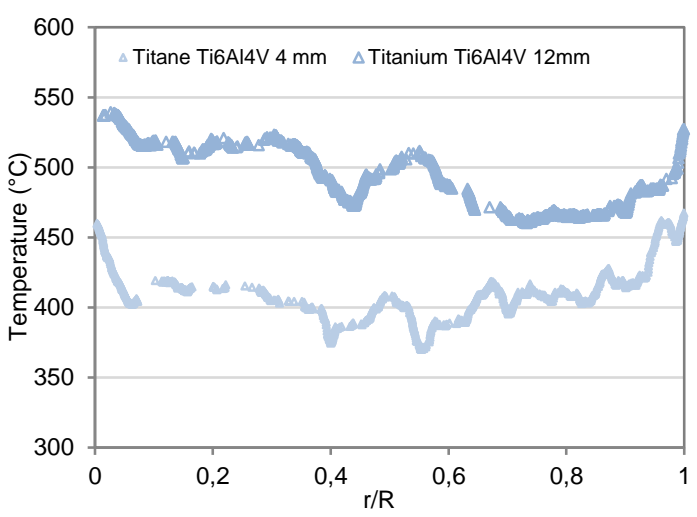

Fig. 9 Temperature distribution functions of axial depth.

These chip evacuation resistance forces probably alter the tribological conditions close to the cutting zone leading to an additive elevation of temperature of the tool and more precisely of the cutting edge.

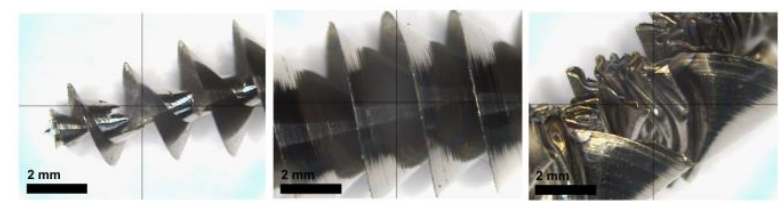

Fig. 10 Chip morphology at (a) tool entrance, (b) $4 \mathrm{~mm}$ and (c) $12 \mathrm{~mm}$ drilling depth.

\subsection{Surface integrity when drilling Ti-6Al-4V}

Microstructure observations in planes $(y, z)$ and $(x, y)$, see figure 4 , reveal various microstructural features. In the workpiece, grains are initially streched in the $z$ direction. Grains size varies from 5 to $10 \mu \mathrm{m}$ large and 10 to $25 \mu \mathrm{m}$ length.

In the plane $(y, z)$, figure 11 , examination of the subsurface does not clearly reveal a microstructure change induced by machining. The mechanical action of the tool in the feed direction does not affect significantly the work material microstructure (4 $\mathrm{mm}$ or $12 \mathrm{~mm}$ drilling depth).

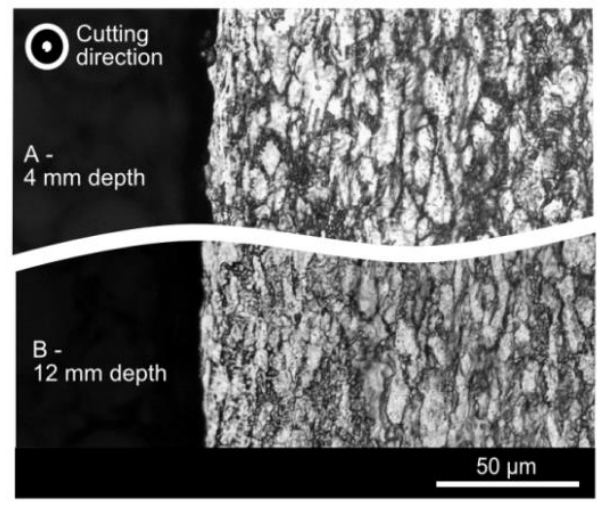

Fig. 11 Microstructure on area $A$ and $B$. 


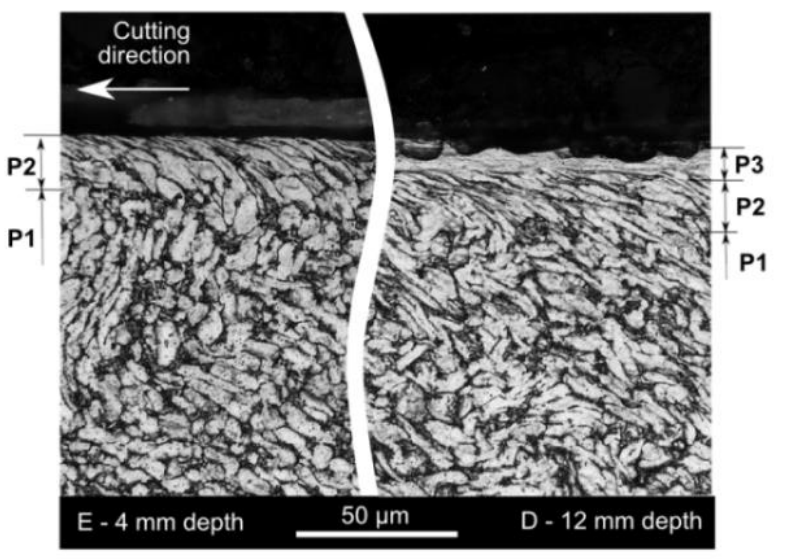

Fig. 12 Microstructure on area $D$ and $E$

In the other hand, observation in the plane $(x, y)$, figure 12 reveals that thermomechanical stresses affect the subsurface microstructure. This effect is amplified with increasing drilling depth. Following Velasquez et al. [18] three affected zones may be defined, figure 12 . The P1 zone corresponds to the bulk material where the machining process does not visually affect this part of the material. In the P2 zone, grains appear deformed in the cutting direction by mechanical action helped by thermal softening of the work material due to high cutting temperature. For the drilling depths of 4 and $12 \mathrm{~mm}$, the thickness of this layer is approximately $15-20 \mu \mathrm{m}$. For the drilling depth of $12 \mathrm{~mm}$, an additional zone P3 is observed just below the machined surface. Its thickness is between 3 and $10 \mu \mathrm{m}$.

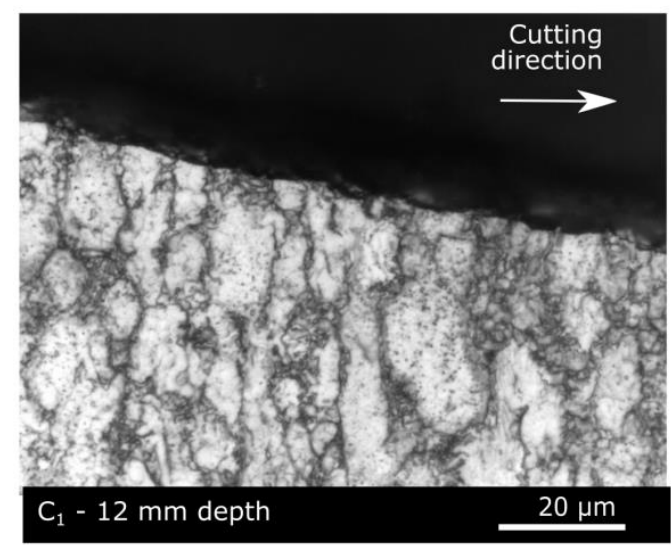

Fig. 13 Microstructure on area $\mathrm{C}_{1}$

The figure 13, corresponds to the plane C1, Figure 5, situated at $1 \mathrm{~mm}$ from the drilling axis, where the cutting speed is reduced $(6 \mathrm{~m} / \mathrm{min})$. As a consequence the microstructure is not visually affected by the drilling process.

About P3 area, obtained for the drilling depth of $12 \mathrm{~mm}$, figure 12, and as shown by Velasquez et al. [18], a drastic elongation of the grains in the cutting direction is observed. Authors consider that the P3 zone is the tertiary shear zone induced by the tool tip contact on the work material. Che Haron and Jawaid [19], about turning Ti-6Al-4V, defines the P3 zone as a white layer of hardened material. This very thin layer appears when machining with nearly worn tool. Chou and Evans [20] suggest that white layer formation seems to be dominantly a thermal process involving phase transformation of the material. When turning a heat resistant super alloy such as Inconel 718, white layer is favored by using worn tool and dry conditions, [21]. Authors attibute white layer to dynamic recrystallization and grains subdivision by a severe plastic deformation.

It can be considered that the P3 zone at $12 \mathrm{~mm}$ drilling depth is the result of two actions. Firstly, the chip is formed as a folded ribbon, sliding on the flute but also sliding against the generated hole, resulting on hot chip bonding particuls on the new generated surface. Secondly, figure 8 shows work material adhesion on the drill margin; during the drilling process under the action of friction between drill margin and drilled hole this ahesion layer is renewed and deposited on drilled hole surface.

Microhardness measurements show two different profiles, function of the location. Generally, the error associated with the hardness measurement with a load of $100 \mathrm{~g}$ is about $5 \mathrm{HK}$.

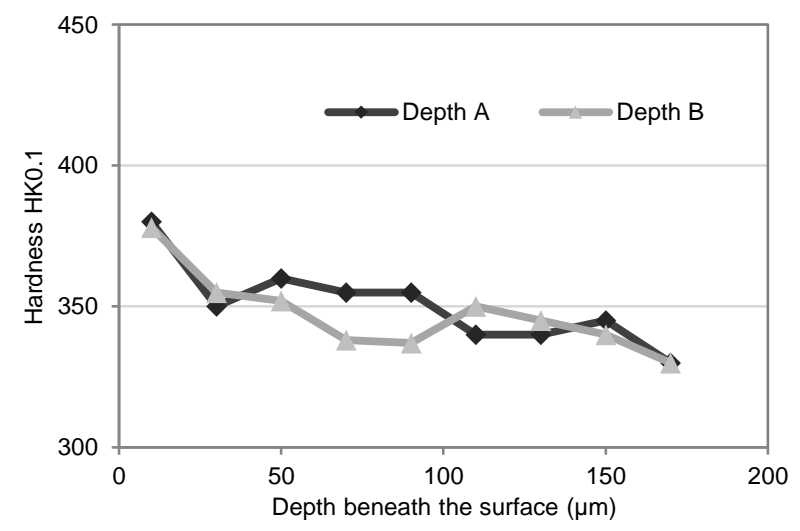

Fig. 14 Micro-hardness on area $A$ and $B$.

In the radial direction perpendicular to the hole axis, and in the areas $A$ and $B$ defined figure 5 , the hardened layer is limited to less than $30 \mu \mathrm{m}$, figure 14 , with a maximum hardness of $380 \mathrm{HK}$ near the drilled hole and a hardness near $350 \mathrm{HK}$ on the bulk material. Hardness profiles are very similar for 4 and $12 \mathrm{~mm}$ drilling depths, and the effect of drilling depth is negligible.

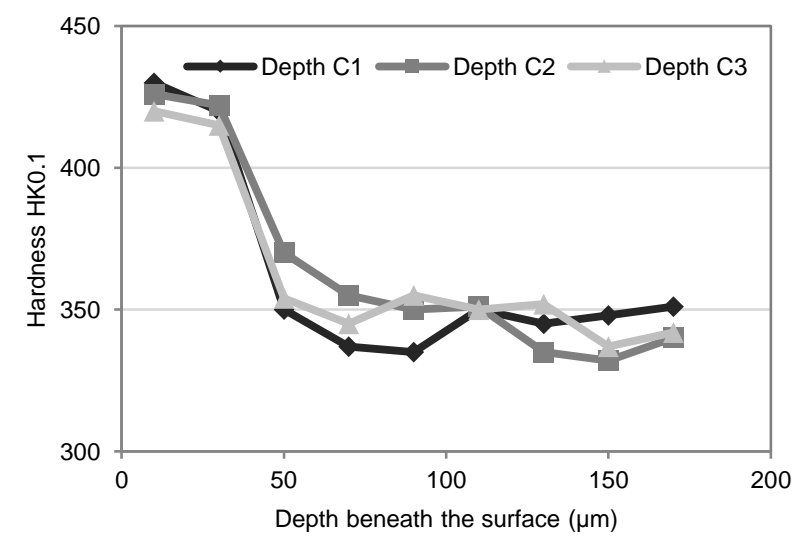

Fig. 15 Micro-hardness on area $\mathrm{C}_{1}, \mathrm{C}_{2}$ and $\mathrm{C}_{3}$. 
In the areas $\mathrm{C} 1, \mathrm{C} 2$ and $\mathrm{C} 3$, see figure 5 , and in the direction perpendicular to the drilled cone, the affected layer is larger, between 30 and $50 \mu \mathrm{m}$, figure 15. The three measured profiles are similar with a maximum hardness of near $425 \mathrm{HK}$ at the drilled surface. Variation of normal rake angle and of cutting speed does not modify the hardness profile.

On the drilled hole surface and sub surface, a hardening process generated by the margin or minor cutting edge is observed, with a grain deformation (P2 zone, areas D and $\mathrm{E}$, Figure 12); however, this hardening is limited. It can be considered that the limited hardening is the result of heat generation due to the drilling process, the hot chip going up along the flute, and the friction between drill margin and drilled hole, and the friction between. A martensitic transformation may happen on the near hole surface, reducing hardness.

\section{CONCLUSIONS.}

An experimental device was developed based on a technique of dynamic thermocouple. It allows an in situ measurement, in a closed area. The temperature distribution along the cutting edge was determined, from the tool tip to the corner radius and for a complex drill geometry

The device was used during dry drilling aeronautical materials aluminium AA7075 and titanium Ti-6Al-4V.

Observations and comparisons were then realised.

1. Wen dry drilling Ti-6Al-4V with a cutting speed of 30 $\mathrm{m} / \mathrm{min}$, temperature along the major cutting edge varies from $450^{\circ} \mathrm{C}$ to $540{ }^{\circ} \mathrm{C}$ at $12 \mathrm{~mm}$ depth. Temperature is much higher than when drilling aluminium AA7075.

2. When dry drilling titanium alloy, a maximum temperature is observed at the tool tip. When dry drilling aluminium alloy, a maximum temperature is obtained at the margin.

3. The temperature distributions along the different cutting ridge are explained by the differences between the thermo-mechanical characteristics of the two materials and the thermal sensitivity to cutting speed and rake angle. When drilling titanium, temperature is particularly influenced by rake angle variation along the cutting edge.

4. When dry drilling Ti-6AI-4V, temperature increases with the depth of cut. Temperature rises of $75{ }^{\circ} \mathrm{C}$ between 4 and $12 \mathrm{~mm}$ depth.

5. Due to the material properties, when drilling Ti6A4V, margin rubs against the cylinder walls, leading to a higher temperature. It results on material bonding on the minor rake face. Drilled hole surface and sub surface are affected with grains elongation and a white layer at $12 \mathrm{~mm}$ drilling depth.

6. The cutting process modifies surface hardness, particularly below the drilled hole.

7. Along the drilled hole, increasing of surface hardness is reduced.

\section{AKNOWLEDGMENT.}

The research is funded by Lorraine University through the Maturation program MachTemp.

\section{REFERENCES.}

[1] Dudzinski, D., Devillez, A., Moufki, A., Larrouquere, D., Zerrouki, V., \& Vigneau, J. (2004). A review of developments towards dry and high speed machining of Inconel 718 alloy. International Journal of Machine Tools and Manufacture, 44(4), 439-456.

[2] Ezugwu, E. O., \& Wang, Z. M. (1997). Titanium alloys and their machinability-a review. Journal of materials processing technology, 68(3), 262-274.

[3] Reissig, L., Völkl, R., Mills, M. J., \& Glatzel, U. (2004). Investigation of near surface structure in order to determine process-temperatures during different machining processes of $\mathrm{Ti}$ 6AI-4V. Scripta Materialia, 50(1), 121-126.

[4] Cantero, J. L., Tardio, M. M., Canteli, J. A., Marcos, M., \& Miguélez, M. H. (2005). Dry drilling of alloy Ti-6Al-4V. International Journal of Machine Tools and Manufacture, 45(11), 1246-1255.

[5] Davies, M. A., Ueda, T., M'saoubi, R., Mullany, B., \& Cooke, A. L. (2007). On the measurement of temperature in material removal processes. CIRP Annals-Manufacturing Technology, 56(2), 581-604.

[6] DeVries, M. F., Wu, S. M., Evaluation of the effects of drill design variables on drill temperature responses, Journal of Engineering for Industry, 1970, pp. 231-238.

[7] Kalidas, S., DeVor, R. E., \& Kapoor, S. G. (2001). Experimental investigation of the effect of drill coatings on hole quality under dry and wet drilling conditions. Surface and Coatings Technology, 148(2), 117-128.

[8] Ozcelik, B., \& Bagci, E. (2006). Experimental and numerical studies on the determination of twist drill temperature in dry drilling: A new approach. Materials \& design, 27(10), 920-927.

[9] Li, R. and Shih, A. J., Tool Temperature in Titanium Drilling, J. Manuf. Sci. Eng 129(4), 740-749 (Apr 01, 2007)

[10] Zeilmann, R. P., \& Weingaertner, W. L. (2006). Analysis of temperature during drilling of Ti-6Al-4V with minimal quantity of lubricant. Journal of materials processing technology, 179(1), 124127

[11] Sato, M., Aoki, T., Tanaka, H., \& Takeda, S. (2013). Variation of temperature at the bottom surface of a hole during drilling and its effect on tool wear. International Journal of Machine Tools and Manufacture, 68, 40-47.

[12] Ueda, T., Nozaki, R., \& Hosokawa, A. (2007). Temperature measurement of cutting edge in drilling-effect of oil mist. CIRP Annals-Manufacturing Technology, 56(1), 93-96.

[13] Beno, T., \& Hulling, U. (2012). Measurement of cutting edge temperature in drilling. Procedia CIRP, 3, 531-536

[14] Bono, M., \& Ni, J. (2002). A method for measuring the temperature distribution along the cutting edges of a drill. Journal of Manufacturing Science and Engineering, 124(4), 921-923.

[15] Jrad, M., Devillez, A., \& Dudzinski, D. (2006, May). Thermomechanical Approach of Drilling Based on A CAD Definition. In Proceedings of the 9th CIRP International Workshop on Modeling of Machining Operations (pp. 247-253)

[16] Chen, P. (1992). Cutting Temperature and Forces in Machining of High-Performance Materials with Self-Propelled Rotary Tool. JSME international journal. Ser. 3, Vibration, control engineering, engineering for industry, 35(1), 180-185. 
[17] Le Coz, G., Marinescu, M., Devillez, A., Dudzinski, D., \& Velnom, L. (2012). Measuring temperature of rotating cutting tools: Application to MQL drilling and dry milling of aerospace alloys. Applied Thermal Engineering, 36, 434-441.

[18] Velásquez, J. P., Tidu, A., Bolle, B., Chevrier, P., \& Fundenberger, J. J. (2010). Sub-surface and surface analysis of high speed machined Ti-6Al-4V alloy. Materials Science and Engineering: $A, 527(10), 2572-2578$.

[19] Che-Haron, C. H., \& Jawaid, A. (2005). The effect of machining on surface integrity of titanium alloy $\mathrm{Ti}-6 \% \mathrm{Al}-4 \% \mathrm{~V}$. Journal of Materials Processing Technology, 166(2), 188-192.

[20] Chou, Y. K., \& Evans, C. J. (1999). White layers and thermal modeling of hard turned surfaces. International Journal of Machine Tools and Manufacture, 39(12), 1863-1881.

[21] Zhou, J., Bushlya, V., Avdovic, P., \& Ståhl, J. E. (2012). Study of surface quality in high speed turning of Inconel 718 with uncoated and coated CBN tools. The International Journal of Advanced Manufacturing Technology, 58(1-4), 141-151. 